\title{
Protein expression of Myt272-3 recombinant clone and in silico prediction of a possible vaccine candidate against Mycobacterium tuberculosis
}

\author{
Mohammed Maikudi Usman ${ }^{1,2}$, Salmah Ismail ${ }^{1 *}$ and Teow Chong Teoh ${ }^{1}$ \\ ${ }^{1}$ Institute of Biological Sciences, Faculty of Science, University of Malaya, 50603 Kuala Lumpur, Malaysia, ${ }^{2}$ Department of \\ Biotechnology, School of Pure and Applied Sciences, Modibbo Adama University of Technology, PMB 2076, Yola, Nigeria \\ *For correspondence: Email: salmah_r@um.edu.my; Tel: +60175778863
}

Received: 12 March 2016

Revised accepted: 21 June 2016

\begin{abstract}
Purpose: To investigate the expression of Myt272-3 recombinant protein and also to predict a possible protein vaccine candidate against Mycobacterium tuberculosis.

Methods: Myt272-3 protein was expressed in pET30a+-Myt272-3 clone. The purity of the protein was determined using Dynabeads $®$ His-Tag Isolation \& Pulldown. Protein sequence was analysed in silico using bioinformatics software for the prediction of allergenicity, antigenicity, MHC-I and MHC-II binding, and B-cell epitope binding.

Results: The candidate protein was a non-allergen with $15.19 \%$ positive predictive value. It was also predicted to be antigenic, with binding affinity to MHC-I and MHC-II, as well as B-cell epitope binding. Conclusion: The predicted results obtained in this study provide a guide for practical design of a new tuberculosis vaccine.
\end{abstract}

Keywords: Vaccine, Mycobacterium tuberculosis, Epitope prediction, Histocompatibility complexes

Tropical Journal of Pharmaceutical Research is indexed by Science Citation Index (SciSearch), Scopus, International Pharmaceutical Abstract, Chemical Abstracts, Embase, Index Copernicus, EBSCO, African Index Medicus, JournalSeek, Journal Citation Reports/Science Edition, Directory of Open Access Journals (DOAJ), African Journal Online, Bioline International, Open-J-Gate and Pharmacy Abstracts

\section{INTRODUCTION}

Tuberculosis is a very serious infectious disease which primarily affects lungs, and is caused by Mycobacterium tuberculosis, an intracellular pathogen [1]. The global threat of tuberculosis, together with the emergence of multi-drug resistant strains of $M$. tuberculosis and coinfection with human immunodeficiency virus (HIV), constitute significant challenges to researchers, physicians and patients [2]. The latent stage of tuberculosis represents an equilibrium state in which the host controls the infection but is unsuccessful in clearing it, thereby allowing the bacterial survival at relatively constant low levels [3]. According to a report by WHO in 2012, 8.6 million people developed tuberculosis and out of that figure, 1.3 million people died as a result of the disease [4]. There is an urgent need of a new and improved vaccine against tuberculosis due to the variable and unreliable efficacy of Bacille CalmetteGuerin (BCG), the current and sole vaccine in use, as well as the emergence of drug-resistant strains of the causative organism [5]. Efficient protection against tuberculosis is achieved in newborns by BCG, but unfortunately the vaccine does not prevent latent infection or reactivation of tuberculosis in adults [6]. In addition, BCG has shown protective efficacies in adult pulmonary tuberculosis, ranging from 0 to 80 per cent [7]. Identification of microbial components responsible for generation of immune responses is the first and most crucial step in the 
development of new vaccines [8]. Immunoinformatics deals with the application of bioinformatics in immunology and is widely accepted due to its usefulness in the design of new vaccines through identification of $\mathrm{T}$-cell epitope, B- cell epitopes and MHCs [9].

In this study, Myt272-3 protein was expressed, purified and characterized. Immunoinformatics strategies were harnessed via software and programs; and antigenicity and epitope-based immunoinformatics studies were carried out using the expressed Myt272-3 protein so as to predict epitope-based information that can assist future vaccine design and development.

\section{EXPERIMENTAL}

\section{Bacterial strains and recombinant clone Myt272-3}

The bacterial strain BL21 (DE3) pLysS was obtained from Invitrogen (USA). The recombinant expressing vector (pET30a+-Myt272-3) used in this study was constructed in the Molecular Bacteriology and Toxicology laboratory, Faculty of Science, University of Malaya. Construction of the clone involved shotgun cloning technique.

\section{Stability testing of the recombinant clone Myt272-3}

Plasmid stability of the clone was tested by the method described by Lanka and Barth with slight modification [10]. Myt272-3 cultures were grown in LB broth overnight at $37^{\circ} \mathrm{C}$. The clones were sub-cultured in LB broth and LB agar and were also incubated overnight; the sub-culturing protocol was carried out repeatedly (10 times). After the tenth and the final transfer into fresh LB broth and agar media, the plasmid DNA was extracted using NucleoSpin ${ }^{\circledR}$ Plasmid (Macherey-Nagel, Germany) based on the manufacturer's instructions.

\section{Restriction digestion analysis}

Restriction endonuclease digestion was carried out using two enzymes, Bam-HI-HF and KpnlHF. Double digestion was done with the two enzymes in order to release the insert. Restriction endonuclease digestion was done in compliance with the conditions stipulated by the supplier (New England Biolabs, USA).

\section{Protein expression, detection and purification}

The recombinant clones of (pET30a+-Myt272-3) were transformed into BL21 (DE3) pLysS strain of E. coli prior to expression. After transformation, the bacteria were grown in LB media containing antibiotics (Kanamycin, 30 $\mathrm{ug} / \mathrm{mL}$ ) at $37{ }^{\circ} \mathrm{C}$ until an absorbance of $0.6-07$ was observed at $600 \mathrm{~nm}$. Protein expression was induced by $1 \mathrm{mM}$ Isopropyl $\beta-D-1-$ thiogalactopyranoside (IPTG). After incubation for three hours, the cells were centrifuged (harvested) at $2500 \times \mathrm{g}$ for $30 \mathrm{~min}$ at $4{ }^{\circ} \mathrm{C}$. The pelleted cells were then stored at $-80{ }^{\circ} \mathrm{C}$ prior to lysis. Four millilitres of bacterial extraction reagent (B-PER, Thermo scientific) was added per gram of pelleted cells and the suspension was pipetted to obtain a homogeneous solution. The solution was incubated for $15 \mathrm{~min}$ followed by centrifugation of lysate for $5 \mathrm{~min}$ at $15000 \times \mathrm{g}$ for separation of soluble protein.

Protein detection was done using sodium dodecyl sulfate polyacrylamide gel electrophoresis (SDS-PAGE) with Tricine-SDS

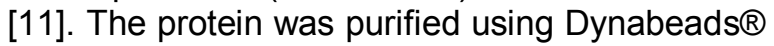
His-Tag Isolation \& Pulldown (Novex life Technologies) according to the manufacture's protocol. The purification method used was designed for the isolation of histidine-tagged protein by magnetic separation; these dynerbeads were coated in a cobalt-based metal affinity chromatographic technique.

\section{MALDI-TOF analysis}

Trypsin digestion of the expressed protein and peptides extraction were carried out according to standard methods described by Bringans et al [12]. The peptides were analysed by MALDITOF/TOF mass spectrometer using a 5800 Proteomics Analyzer [AB Sciex]. The resultant spectra were identified using Mascot sequence matching software [Matrix Science] with MSPnr100 Database (MSPnr100 Taxonomy: Bacteria (Eubacteria); 45,994,506 sequences) accessed in June 2015.

\section{Allergenicity of expressed protein}

Allerginecity of protein was determined with allergen prediction software (http://www.imtech.res.in/raghava/algpred/submi ssion.html) (Algpred) on the basis of similarity of known epitope with any region of protein [13].

\section{Prediction of antigenicity}

Antigenicity predictive value was determined using amino acid sequence of the protein with the help of Vaxijen server, which predicts whether a protein can serve as a probable antigen or not. Vaxijen prediction has a default threshold value of 0.4 and works on the basis of 
auto cross covariance (ACC) (http://www.ddgpharmfac.net/vaxijen/VaxiJen/VaxiJen.html).

\section{Prediction of MHC class I and MHC class II binding epitopes}

MHC class I binding epitopes were predicted using Propred-1 server containing $47 \mathrm{MHC}$ class I alleles [14], while MHC class II binding epitopes were predicted using Propred server having $51 \mathrm{MHC}$ class II allele [15]. The predicted epitopes were further analyzed for antigenicity value using Vaxijen server.

\section{Antibody epitope prediction}

Kolaskar and Tongaonkar antigenicity scale from Immune Epitope Database (IEDB) was used to predict antibody epitope binding, the method utilizes physicochemical properties of amino acid residues and their frequencies of occurrence [16] (http://tools.immuneepitope.org/bcell/).

\section{Statistical analysis}

Mascot sequence software was used for data analysis to determine homology/identity of the protein to phenolpthiocerol synthesis polyketide synthase I PpSA. The level of significance was set at $p<0.05$, with the ion score value $>60$.

\section{RESULTS}

\section{Restriction digestion}

The Myt272-3 recombinant clone was found to have an intact plasmid after it was subjected to series of stability testing up to ten generations. Restriction endonuclease digestion was carried out to determine the size of the insert. Double digestion of the clone with the two restriction enzymes, Bam-HI-HF and Kpnl-HF using cut smart buffer led to generation of two fragments, an insert with approximate size of $113 \mathrm{bp}$ and pET30 vector (Figure 1).

\section{Protein expression and purity}

SDS-PAGE indicated the presence of Myt272-3 recombinant protein with the appearance of a protein band of approximately $10.58 \mathrm{kDa}$, as shown with red arrow on Figure $2 a$. This molecular weight matches the computed value of $10.58 \mathrm{kDa}$ using the EXPASY MW bioinformatics tool. After purification protocol, the clear band of purified his-tag protein was seen, with molecular weight approximately similar to the one obtained using EXPASY MW bioinformatics tool (Figure $2 b)$.

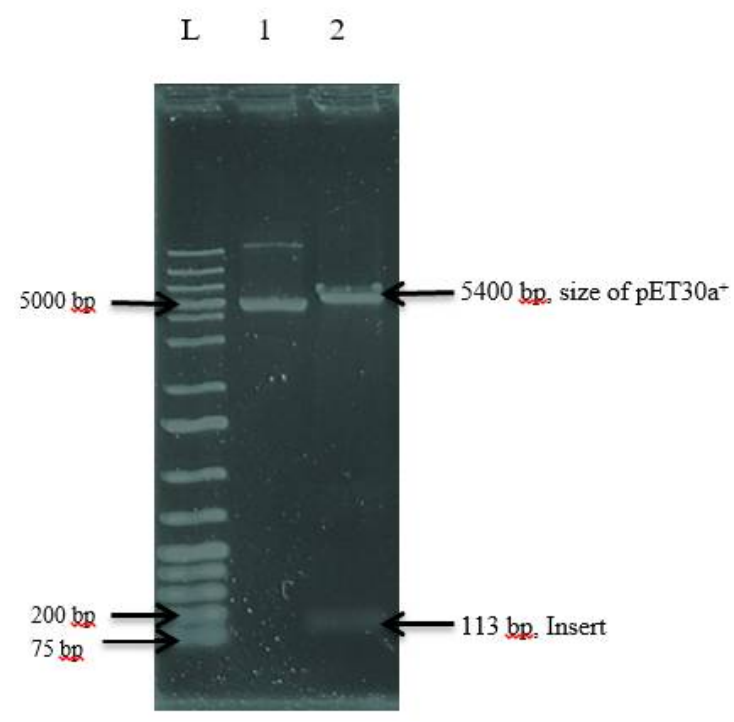

Figure 1: Agarose gel showing insert size. Lane $L$ is GeneRuler $^{\mathrm{TM}} 1 \mathrm{~kb}$ Plus ladder; lane $1 \mathrm{pET30a}^{+}-$ Myt272-3 plasmid; lane 2 indicates the restriction endonuclease restriction fragments formed by double digestion using Bam-HI-HF and Kpnl-HF
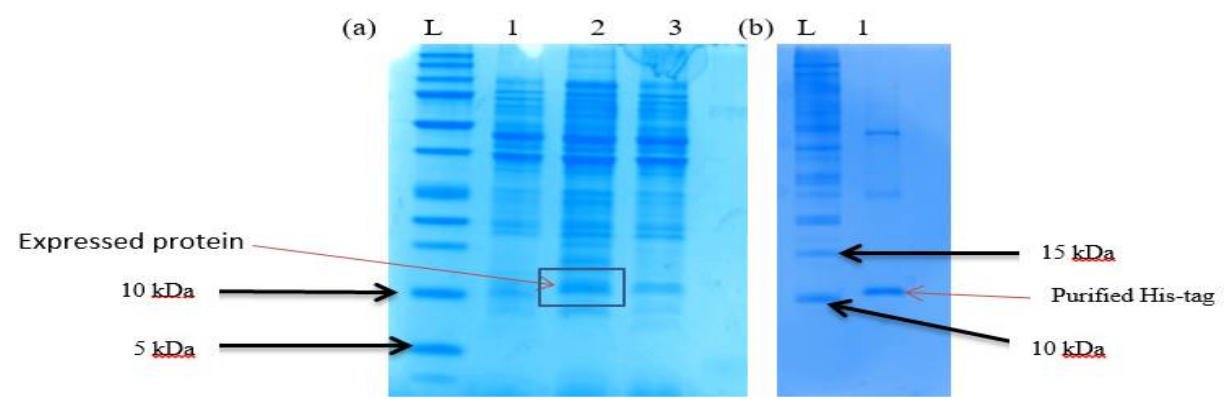

Figure 2: (a) The Expression of His-tag Myt272-3 protein analyzed by SDS-PAGE. Lane L is a Criterion ${ }^{\mathrm{TM}} 10-20$ $\%$ Tris-Tricine protein marker; Lane 1 indicates protein expressed without insert (control); lane 2 shows protein expression at 1mM IPTG where red arrow indicates the expressed his-tag protein. Lane 3 is a non-induced control. (b) Purification of His-tag protein on SDS PAGE. Lane $L$ is a BenchMark ${ }^{\mathrm{TM}}$ His-tagged protein standard (Novex life Technologies); Lane 1 contains purified His-tag protein 


\section{MALDI-TOF}

Analysis of the spectra using Mascot sequence software indicated an identity or extensive homology to phenolpthiocerol synthesis polyketide synthase I PpSA of $M$. tuberculosis, $M$. bovis and $M$. africanus with score values of 157 ; individual ion score $>60$ is an indication of an extensive homology or identity $(p<0.05)$.

The protein was also found to be identical or extensively in homology with multispecies polyketide synthase of $M$. tuberculosis complex $(p<0.05)$ with score value of 157 which is $261.67 \%$ greater than the reported ion score of 60.

\section{Allergenicity and antigenicity}

Allergen prediction result from AlgPred tool indicated that the protein was non-allergen, with score value of -1.4238321 [Threshold $=-0.4$ ]

In addition, the positive predictive value of the protein was $15.19 \%$ (values > 35 indicates allergenicity).

The overall antigenicity value of the protein was 0.4109 (probable antigen) as determined by Vaxijen server (threshold value of 0.4 ).

\section{Predicted MHC class I and MHC class II binding epitopes}

Propred-I (for MHC I) and Propred (MHC II) were used for prediction of T-cell epitopes for the Myt272-3 protein. Identification of MHC-binding peptides and their subset of T-cell epitopes assist in improving our understanding of specificity of immune responses; it is also important for in discovery of vaccines [17].

MHC class I and class II binding prediction results are shown in Tables 1 and 2, respectively.

All the alleles showed good match to the protein with log scores of all the peptides greater than their respective threshold values at $4 \%$, and Vaxijen values greater than 0.4 (Table 1 for MHC I).

For MHC II, only alleles DRB1_1304 and DRB1_1321 matched the protein sequence, with peptide scores greater than their respective threshold values, and Vaxijen value $\geq 0.4$ (Table 2).

\section{Antibody epitope prediction}

Table 3: The predicted residue scores by Kolaskar and Tongaonkar antigenicity with the threshold value of 1.0

\begin{tabular}{lllc}
\hline Start & End & Peptide & Score \\
\hline 36 & 42 & LGTLSLA & 1.087 \\
37 & 43 & GTLSLAD & 1.032 \\
38 & 44 & TLSLADL & 1.086 \\
39 & 45 & LSLADLG & 1.081 \\
40 & 46 & SLADLGV & 1.1 \\
41 & 47 & LADLGVS & 1.1 \\
42 & 48 & ADLGVSS & 1.066 \\
43 & 49 & DLGVSSR & 1.039 \\
44 & 50 & LGVSSRD & 1.039 \\
45 & 51 & GVSSRDA & 1.012 \\
46 & 52 & VSSRDAV & 1.085 \\
47 & 53 & SSRDAV & 1.085 \\
48 & 54 & SRDAVVL & 1.119 \\
49 & 55 & RDAVVLS & 1.119 \\
50 & 56 & DAVVLSG & 1.119 \\
51 & 57 & AVVLSGE & 1.117 \\
52 & 58 & VVLSGEL & 1.143 \\
53 & 59 & VLSGELS & 1.09 \\
54 & 60 & LSGELSE & 1.014 \\
55 & 61 & SGELSEL & 1.014 \\
56 & 62 & GELSELL & 1.048 \\
57 & 63 & ELSELLG & 1.048 \\
58 & 64 & LSELLGR & 1.051 \\
59 & 65 & SELLGRT & 1.003 \\
60 & 66 & ELLGRTV & 1.056 \\
61 & 67 & LLGRTVS & 1.079 \\
62 & 68 & LGRTVSP & 1.052 \\
63 & 69 & GRTVSPI & 1.038 \\
\hline & & &
\end{tabular}

As shown in Table 3, and Figure 3 (center yellow region), the most possible epitopes predicted for antigenic Myt272-3 protein consist of amino acids from 48-58 (SRDAVVL-VVLSGEL) with score $>1.0$. Another possible epitope is from amino acids 40-47 (SLADLGV-LADLGVS).

The prediction was also done by ABCpred, Artificial neural network based B-cell epitope prediction server (http://www.imtech.res.in/raghava/abcpred/). This indicated that SRDAVVLSGEL (48-58) is the most probably epitope with highest score.

\section{DISCUSSION}

Myt272-3 protein was expressed and purified to yield a band of approximate MW $10.58 \mathrm{kDa}$ which conformed with the MW computed by EXPASY MW bioinformatics tool. The protein was found to be a non-allergen. It has been reported that a protein can be classified as an allergen when it shows $>35 \%$ identity with a familiar allergen over a window of 80 amino acids, or presence of six 6 contiguous amino acids present in a known allergen $[18,19]$. 
Table 1: MHC-I binding peptides and antigenicity scores of sequences according to VaxiJen serve

\begin{tabular}{|c|c|c|c|c|c|c|c|}
\hline \multirow[t]{2}{*}{ Allelles } & \multirow{2}{*}{$\begin{array}{c}\text { Threshold } \\
\text { value at } \\
4 \%\end{array}$} & \multirow[t]{2}{*}{ Sequence } & \multicolumn{4}{|c|}{$\begin{array}{l}\text { Score achievable by any peptide on } \\
\text { log scale }\end{array}$} & \multirow{2}{*}{$\begin{array}{l}\text { Vaxijen } \\
\text { value } \\
\text { (Threshold } \\
=0.4 \text { ) }\end{array}$} \\
\hline & & & position & $\begin{array}{l}\text { Real } \\
\text { score }\end{array}$ & $\begin{array}{l}\text { Log } \\
\text { score }\end{array}$ & $\begin{array}{l}\text { Highest } \\
\text { score }\end{array}$ & \\
\hline HLA-A1 & -1.553 & LADLGVSSR & 41 & 5 & 1.6094 & 12.324 & 1.2945 \\
\hline HLA-A2 & 0.693 & VLSGELSEL & 53 & 27.76 & 3.3237 & 15.156 & 0.7474 \\
\hline HLA-A*0201 & 1.143 & VLSGELSEL & 53 & 83.53 & 4.4252 & 17.857 & 0.7474 \\
\hline \multirow[t]{2}{*}{ HLA-A*0205 } & 0.519 & VLSGELSEL & 53 & 23.80 & 3.1697 & 10.499 & 0.7474 \\
\hline & & GVSSRDAVV & 45 & 4 & 1.3863 & 10.499 & 0.9744 \\
\hline \multirow[t]{2}{*}{ HLA-A3 } & -0.799 & VLSGELSEL & 53 & 1.35 & 0.3001 & 15.620 & 0.7474 \\
\hline & & LLGRTVSPI & 61 & 1.8 & 0.5878 & 15.620 & 0.9916 \\
\hline HLA-A*3101 & -1609 & LADLGVSSR & 41 & 0.2 & -0.9163 & 11.408 & 1.2945 \\
\hline HLA-A*3302 & -0.105 & LADLGVSSR & 41 & 3 & 1.0986 & 6.109 & 1.2945 \\
\hline HLA-A68.1 & 1.609 & GVSSRDAVV & 45 & 6 & 1.7918 & 10.609 & 0.9744 \\
\hline \multirow{3}{*}{ HLA-A2.1 } & 105.100 & VLSGELSEL & 53 & 119.8 & 119.800 & 145.700 & 0.7474 \\
\hline & & LLGRTVSPI & 61 & 117.9 & 117.900 & 145.700 & 0.9916 \\
\hline & & GVSSRDAVV & 45 & 108.9 & 108.900 & 145.700 & 0.9744 \\
\hline HLA-B*2702 & 0.000 & RTVSPIDFW & 64 & 1.5 & 0.4055 & 10.309 & 0.5912 \\
\hline HLA-B*2705 & 2.996 & VLSGELSEL & 53 & 30 & 3.4012 & 10.309 & 0.7474 \\
\hline HLA-B*3501 & 0.693 & VSSRDAVVL & 46 & 6 & 17.918 & 8.882 & 0.5123 \\
\hline HLA-B*3701 & 0.405 & LSGELSELL & 54 & 5 & 1.6094 & 8.006 & 0.4193 \\
\hline HLA-B40 & 0.000 & RTVSPIDFW & 64 & 3 & 1.0986 & 8.476 & 0.5192 \\
\hline HLA-B*5101 & 1.649 & LGVSSRDAV & 44 & 57.2 & 4.0466 & 10.157 & 0.9816 \\
\hline HLA-B*5102 & 2.078 & LGVSSRDAV & 44 & 120 & 4.7875 & 11.671 & 0.9816 \\
\hline HLA-B*5103 & 0.884 & LGVSSRDAV & 44 & 40 & 3.6889 & 7.567 & 0.9816 \\
\hline \multirow[t]{2}{*}{ HLA-B*5201 } & 1.974 & LGVSSRDAV & 44 & 7.5 & 2.0149 & 9.989 & 0.9816 \\
\hline & & GVSSRDAVV & 45 & 10 & 2.3026 & 9.989 & 0.9744 \\
\hline \multirow[t]{2}{*}{ HLA-B*5301 } & 104.800 & LGVSSRDAV & 44 & 106.23 & 106.2300 & 150.500 & 0.9816 \\
\hline & & VSSRDAVVL & 46 & 105.84 & 105.8400 & 150.00 & 0.5123 \\
\hline HLA-B*51 & 104.920 & LGVSSRDAV & 44 & 115.49 & 115.4900 & 157.000 & 0.9816 \\
\hline \multirow[t]{2}{*}{ HLA-B*5801 } & -0.223 & LSGELSELL & 54 & 6 & 1.7981 & 9.350 & 0.4193 \\
\hline & & RTVSPIDFW & 64 & 288 & 5.6630 & 9.350 & 0.5912 \\
\hline HLA-B60 & 1.386 & VSSRDAVVL & 46 & 16 & 2.7726 & 8.955 & 0.5123 \\
\hline HLA-B61 & 0.000 & LGVSSRDAV & 44 & 2 & 0.6931 & 7.879 & 0.9816 \\
\hline \multirow[t]{2}{*}{ HLA-B62 } & 0.693 & DLGVSSRDA & 43 & 4 & 1.3863 & 9.199 & 0.7212 \\
\hline & & LLGRTVSPI & 61 & 4 & 1.3863 & 9.199 & 0.9916 \\
\hline HLA-Cw0401 & 1.577 & VLSGELSEL & 53 & 8 & 2.0794 & 9.342 & 0.7474 \\
\hline HLA-Cw*0602 & 1.482 & LSGELSELL & 54 & 6 & 1.7918 & 4.380 & 0.4193 \\
\hline MHC-Db & 1.276 & LSGELSELL & 54 & 22.217 & 3.1009 & 12.671 & 0.4193 \\
\hline \multirow{2}{*}{ revised } & & VSSRDAVVL & 46 & 9.374 & 2.2380 & 12.671 & 0.5123 \\
\hline & 0.365 & LSGELSELL & 54 & 1.452 & 0.3729 & 6.346 & 0.4193 \\
\hline \multirow[t]{2}{*}{$\mathrm{MHC}-\mathrm{Kb}$} & & VSSRDAVVL & 46 & 1.2 & 0.1823 & 6.346 & 0.5123 \\
\hline & 4.236 & LSGELSELL & 54 & 57.6 & 4.0535 & 8.289 & 0.4193 \\
\hline $\begin{array}{l}\text { MHC-Kd MHC- } \\
\text { Ld }\end{array}$ & 2.015 & VSSRDAVVL & 46 & 25 & 3.2189 & 6.554 & 0.5123 \\
\hline
\end{tabular}

Table 2 : MHC- II binding peptides and antigenicity scores of sequences according to Vaxijen server

\begin{tabular}{lclcccc}
\hline Allelle & $\begin{array}{c}\text { Threshold } \\
\text { for } \mathbf{3} \%\end{array}$ & Sequence & Position & Score & $\begin{array}{c}\text { Highest } \\
\text { score } \\
\text { achievable }\end{array}$ & $\begin{array}{c}\text { Vaxijen value } \\
\text { (Threshold = } \\
\mathbf{0 . 4 )}\end{array}$ \\
\hline DRB1_0402 & 1.8 & LLGRTVSPI & 60 & 2.4 & 9.6 & -0.9916 \\
DRB1_0801 & 1.8 & LLGRTVSPI & 60 & 2.3 & 8.6 & -0.9916 \\
DRB1_0802 & 1.0 & LLGRTVSPI & 60 & 2.1 & 8.0 & -0.9916 \\
DRB1_0804 & 1.6 & LLGRTVSPI & 60 & 3.1 & 8.0 & -0.9916 \\
DRB1_0806 & 2.4 & LLGRTVSPI & 60 & 3.3 & 8.6 & -0.9916 \\
DRB1_0813 & 1.9 & LLGRTVSPI & 60 & 3.9 & 8.7 & -0.9916 \\
DRB1_1304 & 2.6 & VVLSGELSE & 51 & 2.8 & 9.0 & 0.8284 \\
DRB1_1321 & 2.2 & VVLSGELSE & 51 & 2.8 & 8.9 & 0.8284 \\
\hline
\end{tabular}




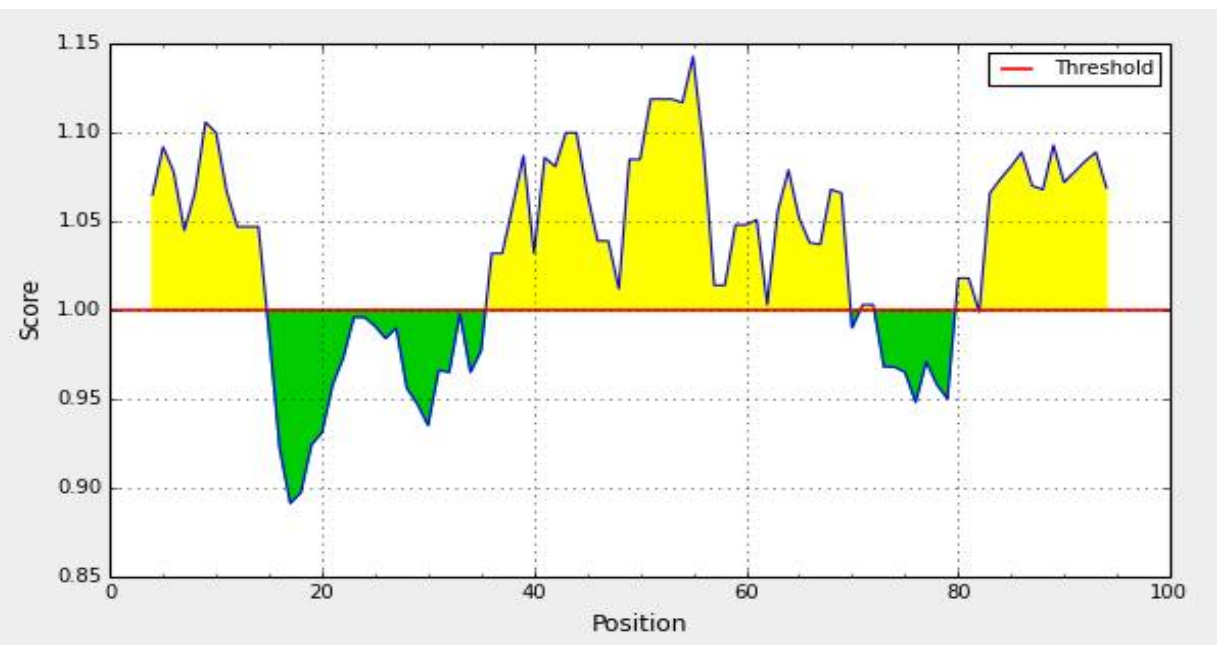

Figure 3: Kolaskar and Tongaonkar antigenicity plot of Myt272-3 recombinant protein withThreshold: 1.0 (horizontal redline). The yellow colors above the threshold represent higher scores, while green portions indicate unfavorable regions in relation to the region of interest

AlgPred is considered one of the web-based servers used to predict allergens through their amino acid sequences [20]. Protein Blast of the query protein sequence also indicated homology of $81 \%$ with phenolpthiocerol synthesis polyketide synthase I PpSA of $M$. tuberculosis, which is consistent with the results obtained from MALDI-TOF.

It has been reported that polyketide synthase is involved in the biosynthesis of unique cell surface lipids; Mycobacterium tuberculosis cell envelope contain the cell surface lipids that link the host and the pathogen [21]. Phthiocerol and phenolphthiocerol diesters were reported also as important virulence factors of the two main mycobacterial pathogens $(M$. tuberculosis and $L$. leprae) in human [22]. The protein blast result also indicated non-homology with human protein. It is known that vaccines are considered good when they do not show homology with human proteins, thus eliminating likelihood of their triggering on autoimmune response [8].

In this study, it was found that thirty (30) allelles of $\mathrm{MHC}$ I bind peptides with binding scores higher than the threshold score of each peptide. It was also found that antigenicity values of all the peptides were above the Vaxijen server threshold (0.4). This strongly indicates that Myt272-3 protein is a probable antigenic protein for development of tuberculosis vaccine. Epitope LADLGVSSR at position 41 was found to have the highest antigenicity value of (1.2945) among all epitopes. This is an indication of maximum binding affinity.

The predicted peptides, LLGRTVSPI and VVLSGELSE at positions 60 and 51, respectively were found to bind eight different MHC II alleles with binding scores greater than their respective threshold value at $4 \%$, but further antigenicity analysis using Vaxijen scale revealed only peptide, VVLSGELSE had antigenicity activity with the score of 0.8284 that is higher than the threshold score of 0.4 .

It has been observed that computational predictions of HLA-II binding are inferior when compared with their HLA-I counterparts, due to factors which include insufficient data used by developers of prediction methods for HLA-II binding peptides, and the fact that HLA-II molecules have relatively permissive binding sites for peptide, a property which limits their specificities [23]. The prediction of potential Bcell epitope was carried out via amino acid-based method. All epitopes with antigenic value greater than the threshold value of 1.0 were considered potential antigenic determinants. The results show that all the epitopes from position 36 to 69 satisfied the threshold value requirement for antigenicity. The highest antigenicity scores were recorded in three peptides - SRDAVVL, RDAVVLS and DAVVLSG with score of 1.119 [24].

\section{CONCLUSION}

Development of efficient and cost-effective vaccine can be achieved through immunoinformatics-based vaccine design. The predicted results obtained in the present work provide a guide for practical design of new tuberculosis vaccine. In silico analysis of the protein reveals that it is a non-allergen with antigenic activity. It binds both $\mathrm{MHC} \mathrm{I}$ and II but to a lesser extent with the latter, probably due to the fact that computational predictions of HLA-II 
binding are inferior when compared with their HLA- I counterparts. The protein possesses Bcell epitopes. These predictive findings have implications for design and development of Mycobacterium tuberculosis vaccines.

\section{DECLARATIONS}

\section{Acknowledgement}

The authors wish to thank University of Malaya for supporting this research through the following grants: PG238-2014B: PPP, RG064-12BIO and RG523/13HTM.

\section{Conflict of Interest}

No conflict of interest associated with this work.

\section{Contribution of Authors}

The authors declare that this work was done by the authors named in this article and all liabilities pertaining to claims relating to the content of this article will be borne by them.

\section{REFERENCES}

1. Pitt JM, Blankley S, McShane H, O'Garra A. Vaccination against tuberculosis: how can we better BCG? Microb Pathog 2013; 58: 2-16.

2. Valdés I, Montoro E, Mata-Espinoza D, Asin O, BarriosPayan J, Francisco-Cruz A, Valdivia JA, HernándezPando R. Immunogenicity and protection conferred by Mycobacterium habana in a murine model of pulmonary tuberculosis. Tuberculosis 2014; 94(1): 65-72.

3. Fallahi-Sichani M, El-Kebir M, Marino S, Kirschner DE, Lindermann JJ. Multiscale computational modeling reveals a critical role for TNF- $\alpha$ receptor 1 dynamics in tuberculosis granuloma formation. J Immunol 2011; 186(6): 3472-3483.

4. World Health Organisation. Global tuberculosis report 2013. WHO 2013; Geneva, Switzerland.

5. Sarmiento ME, Calero R, Camacho $F$, Reyes $F$, Hossain MM, Gonzalez GS, Norazmi MN, Acosta A. Immunoinformatics study on highly expressed Mycobacterium tuberculosis genes during infection. Tuberculosis 2014; 94(5): 475-481.

6. Mirlekar B, Pathak S, Pathade G. Mycobacterium tuberculosis: approach to development of improved strategies for disease control through vaccination and immunodiagnosis. Indian J. Lepr 2013; 85(2): 65

7. Yuan W, Dong N, Zhang L, Liu J, Lin S, Xiang Z, Qiao H, Tong W, Qin C. Immunogenicity and protective efficacy of a tuberculosis DNA vaccine expressing a fusion protein of Ag85B-Esat6-HspX in mice. Vaccine 2012, 30(14): 2490-2497.
8. Monterrubio-López GP. Identification of novel potential vaccine candidate against tuberculosis based on reverse vaccinology. Biomed Res Int 2015.

9. Oany AR, Ahmad SAI, Hossain MU, Jyoti TP. Identification of highly conserved regions in L-segment of Crimean-Congo hemorrhagic fever virus and immunoinformatic prediction about potential novel vaccine. Adv App Bioinform Chem 2015; 8: 1

10. Lanka E, Barth P. Plasmid RP4 specifies a deoxyribonucleic acid primase involved in its conjugal transfer and maintenance. J Bacteriol 1981; 148(3): 769-781.

11. Schägger H. Tricine-SDS PAGE. Nat Protoc 2006; 1: 1622.

12. Bringans S, Kendrick TS, Lui J, Lipscombe R. A comparative study of the accuracy of several de novo sequencing software packages for datasets derived by matrix-assisted laser desorption/ionization and electrospray. Rapid Commun Mass Spectrom 2008; 22(21): 3450-3454

13. Saha S, Raghava GPS. AlgPred: prediction of allergenic proteins and mapping of IgE epitopes. Nucleic Acids Res 2006; 34: 202-209.

14. Singh $H$, Raghava G. ProPred1: prediction of promiscuous MHC Class-I binding sites. Bioinformatics 2003; 19(8): 1009-1014.

15. Singh H, Ranghava G. PropPred: prediction of HLA-DR binding sites. Bioinformatics 2001; 17(12): 1236-1237.

16. Kolaskar A, Tongaonkar PC. A semi-empirical method for prediction of antigenic determinants on protein antigens. FEBS Lett 1990; 276(1): 172-174.

17. Lin HH, ray S, Tongchusak S, Reinherz EL, Brusic V. Evaluation of MHC class I peptide binding prediction servers: applications for vaccine research. BMC immunol 2008; 9(1): 8.

18. Dang X, Lawrence CB. Allerdictor: fast allergen prediction using text classification techniques. Bioinformatics 2014; 30(8): 1120-1128.

19. Food and Agriculture Organisation/World Health Organisation. Evaluation of allergenicity of genetically modified foods: report of a joint FAOWHO expert consultation on allerginecity of foods derived from biotechnology. FAO 2001; Rome, Italy.

20. Sircar G, Saha B, Bhattacharya SG, Saha S. In silico prediction of allergenic proteins. In: Rajat, Ke D, Namrata $T$, editors. Immunoinformatics, Methods in molecular biology. Springer; 2014. 375-388.

21. Passermar C, Arbués A, Malaga W, Mercier I, Moreau F, Lepourry L, Neyrolles O, Guilhot C, Astarie-Dequeker C. Multiple deletions in the polyketide synthase gene repertoire of Mycobacterium tuberculosis reveal functional overlap of cell envelope lipids in hostpathogen interactions. Cellular Microbiol 2014; 16(2): 195-213.

22. Onwueme KC, Vos CJ, Zurita J, Ferreras JA, Quadri $L E N$. The dimycocerosate ester polyketide virulence factors of mycobacteria. Prog Lipid Res 2005; 44(5): 259-302.

Trop J Pharm Res, July 2016; 15(7): 1399 
23. Lin HH, Zhang GL, Tongchusak S, Reinherz EL, Brusic V. Evalution of MHC-Il peptide binding prediction servers: applications for vaccine research. BMC Bionformatics 2008; 9((Supp.12)): S22.
24. Assis L, Sousa JR, Pinto NFS, Silva AA, Vaz AFM, Andrade PP, Carvalho EM, Melo MA. B-cell epitopes of antigenic proteins in Leishmania infantum: an in silico analysis. Parasite Immunol 2014; 36(7): 313-323. 